\title{
Blood tyrosine determination for monitoring glucocorticoid therapy
}

\author{
Irma Th. Rass* \\ Center of Theoretical Problems of Physico-Chemical Pharmacology, Russian Academy of Sciences (until 2007), Moscow, \\ Russia.
}

GSC Biological and Pharmaceutical Sciences, 2021, 16(03), 245-266

Publication history: Received on 08 August 2021; revised on 25 September 2021; accepted on 27 September 2021

Article DOI: https://doi.org/10.30574/gscbps.2021.16.3.0266

\begin{abstract}
Glucocorticoid (GC) preparations are used in medicine for more than 70 years as the most powerful anti-inflammatory drugs also possessing immunosuppressive, anti-allergic, and antitoxic properties. However, administration of these unique preparations is associated with nearly inevitable severe adverse effects and a difficulty of their withdrawal. These adverse effects are caused not by toxicity of GC preparations, but are manifestations of their hormonal features. GC preparations are synthetic analogs of GC hormones which directly or indirectly participate in the regulation of virtually all reactions and processes in the body. Nevertheless, in clinical practice there is no index of tissue provision with GCs and real need in these hormones (or preparations). In this paper, blood tyrosine level was shown to characterize the tissue provision with GCs on two models: adrenalectomy in rats and the replacement GC therapy in congenital adrenal hyperplasia. Determination of blood tyrosine level made it possible to reveal the insufficiency of tissue provision with GGs in patients with bronchial asthma during the period of attacks. In patients with systemic lupus erythematosus, GC preparations were shown to be favorable on the background of increased blood tyrosine, i.e. on the insufficient tissue provision with GCs, and until the normalization of blood tyrosine, i.e. until the compensation of the hormonal insufficiency. On the background of normal blood tyrosine GC preparations in SLE were ineffective and side effects appeared rapidly. These observations allowed me to propose blood tyrosine level as a laboratory parameter for monitoring GC therapy.
\end{abstract}

The present paper consists of two parts: I) short reviews of the literature prerequisites for the proposal; II) the description of the author's studies on blood tyrosine behavior in comparison with delivery and efficiency of glucocorticoid hormones or preparations in experiment (adrenalectomy in rats) and in some pathologies: congenital adrenal hyperplasia, bronchial asthma, and systemic lupus erythematosus.

Keywords: Glucocorticoid therapy; Glucocorticoid hormones; Tissue provision with glucocorticoids; Hepatic tyrosine aminotransferase; Tyrosine metabolism; Blood tyrosine versus glucocorticoids

\section{Introduction}

The modern clinical medicine is characterized by using of highly efficient drugs capable of deep intervention into mechanisms of pathologies. Among such drugs, preparations of glucocorticoid (GC) hormones are especially interesting and important.

A specific feature of these hormonal preparations is their administration in the treatment of various non-endocrine diseases: rheumatism, collagenoses, bronchial asthma, severe dermatoses, acute lympho- and myeloleukemia, glomerulonephritis, hemolytic anemia, etc. GC preparations are the most efficient anti-inflammatory preparations also possessing anti-allergic, immunosuppressive, antitoxic, and anti-shock action. However, the use of these drugs, unique

\footnotetext{
${ }^{*}$ Corresponding author: Irma Th. Rass
}

Center of Theoretical Problems of Physico-Chemical Pharmacology, Russian Academy of Sciences (until 2007), Moscow, Russia. 
in the broad spectrum and expression of therapeutical properties, is associated with severe adverse effects and the difficulty and sometimes impossibility to withdraw them. The adverse effects of GC therapy are not caused by toxicity of GC preparations, but are manifestations of their hormonal nature - either of their excess, or of disorders in the negative feedback regulation in the hypothalamus-pituitary-adrenals (HPA) system. The problem of efficient and riskfree administration of GC preparations emerged concurrently with their appearance as therapeutic agents, more than 70 years ago, and is still urgent because they are irreplaceable in clinical practice.

During 70 years, two approaches are used for overcoming the adverse effects of GC therapy: 1) synthesis of new preparations on the same structure of cholesterol molecule in order to separate the desired therapeutical properties from the adverse effects caused by hormonal features of GC preparations, and 2) the careful following the empirical schemes and medicamentous preventing the adverse effects.

However, there is the third approach for preventing the adverse effects of GC therapy: the approach based not on the struggle against the hormonal features of GC preparations, but on taking these features into account on the administration of these preparations.

GC hormones produced by the adrenal cortex are involved in the regulation of virtually all metabolic reactions and physiological processes in the body. Therefore, it was reasonable to compare a manifestation of the regulatory effect of GC hormones with therapeutic effect of GC preparations. For this purpose, a GC-dependent hepatic enzyme tyrosine aminotransferase (TAT) which is frequently used as a representative parameter of GC action on metabolism would be suitable. However, TAT is the tissue enzyme and cannot be measured in blood, but it determines the blood level of amino acid tyrosine.

This paper presents the literature prerequisites for the proposal of comparing blood tyrosine level with GCs: a short history of CG therapy, of functions of GC hormones in the body, of hepatic tyrosine aminotransferase, and of blood tyrosine behavior. The paper presents also a review of the author's studies on blood tyrosine behavior in comparison with various situations of GC entering into the body: in the experiment (adrenalectomy on rats) and in the real situations of GC therapy: congenital adrenal hyperplasia, bronchial asthma, systemic lupus erythematosus.

\section{Literature prerequisites}

\subsection{Glucocorticoid therapy}

The emergence of glucocorticoids in medicine was triumphant.

On September 21, 1948, Doctor Philip S. Hench in the Mayo Clinic injected cortisone isolated by Edward Kendall from the adrenal cortex to a 29-year-old woman with rheumatoid arthritis. After three injections the patient who was treated unsuccessfully during preceding four years and nearly did not move because of joint constraint and pain, could rise up from the bed and walk. This was not an occasional finding: during several years, Dr. Hench searched for a natural product of the human body which would be able to improve conditions of patients with rheumatoid arthritis. He knew the works of Hans Selye, and his interest for products of the adrenals was reasonable. Cortisone occurred to be a powerful therapeutic agent also in other patients of the Mayo Clinic with various diseases [1-4].

In July 1949, the report by Dr. Hench at the International Rheumatological Congress in New York was a sensation. Glucocorticoids literally streamed into clinical medicine. The results of their administration were so impressive that already in 1950 Philip S. Hench, Edward C. Kendall and Tadeus Reichstein were awarded the Nobel Prize in Physiology and Medicine for "Their discoveries relating to the adrenal cortex hormones, their structure and biological effects".

The subsequent decades became a period of extremely extensive spontaneous clinical trials of new preparations. "Glucocorticoids were dropped into eyes, introduced into nasal passages and bronchi, injected into muscles and blood channel, smeared as ointments, introduced into the rectum, and, finally, swallowed as tablets" [5]. Glucocorticoid preparations were found to be the most efficient agents in rheumatoid arthritis, collagenoses, bronchial asthma, psoriasis, inflammatory bowel diseases, sarcoidosis, hemolytic anemia, etc. In such severe and virtually lethal autoimmune disease as systemic lupus erythematosus, GCs occurred to be the only drugs that allowed clinicians to save life of the patients. Glucocorticoids acted as the most powerful anti-inflammatory drugs possessing also anti-allergic, immunosuppressive, antitoxic, anti-shock effects. They were unique and incomparable in their therapeutic activities [6, 7].

However, rather rapidly the initial euphoria was replaced by confusion and then by disappointment. Alongside with reports about favorable results of these spontaneous trials, there were also reports on serious adverse effects, such as 
disorders in mineral metabolism, hypertension, steroid diabetes, secondary infections, osteoporosis and osteonecrosis, psychoses, etc. Moreover, it was difficult and sometimes impossible to withdraw GC preparations because of exacerbation of the main disease and adrenal insufficiency. It was clear that the adverse effects were caused either by hypercorticism manifested by the Cushing syndrome signs or by adrenocortical failure because of disorders in the negative feedback regulation in the hypothalamus-pituitary-adrenals (HPA) system. In some cases, the secondary adrenocortical failure even could be the cause of patients' death at occasional stress situations. Already in 1960, the risk of severe corticothetrapy-associated complications was considered inevitable [8], and after 25 years of corticosteroid therapy, Prof. Y.A. Sigidin wrote that prescribing corticosteroid preparations to patients with rheumatism evidenced the incompetence of the physician [9].

Notwithstanding the danger, GC preparations remain in clinical practice.

From the very beginning, it was obvious that the adverse effects of GC preparations were associated with their hormonal nature, but at the same time their therapeutic action did not depend on the background of endogenous GC hormones of the patients, including their increased level. This strange finding resulted in the idea that GC preparations possessed specific therapeutic properties and stimulated careful studies on the anti-inflammatory action of GC preparations. GCs were shown to act on virtually all components of the inflammatory and immune response: they inhibited inflammation mediators, stabilized lysosomal membranes, normalized the permeability of cellular membranes, suppressed the lymphoid-reticular system, synthesis of antibodies and formation of autoimmune complexes, etc. GC preparations increased expression of genes encoding anti-inflammatory proteins and suppressed transcription of genes responsible for generation and release of inflammatory mediators. Glucocorticoids also induced apoptosis of immunocompetent cells [10-15].

To overcome the problems associated with administration of GC preparations, chemists and pharmacologists tried to separate the therapeutic properties from the undesired manifestations of their hormonal features, such as the influence on the carbohydrate and mineral metabolism and on suppression of the HPA system [16-18]. This problem was partially solved by addition to the basic cholesterol structure of the natural GC hormones of atoms or groups of atoms. The antiinflammatory activity of such synthetic GC preparations (prednisolone, dexamethasone, methylprednisolone, triamcinolone, etc.) was stronger than of their natural prototype, but they also caused adverse effects, and the adrenal cortex suppression was deeper and more prolonged. Later, many drugs were synthesized on the same structural basis for special purposes: lazaroids, or 21-aminosteroids [19, 20], liposomal corticosteroids [21], nitrosteroids [22], as well as promising SEGRAs or SEGRMs preparations (Selective Glucocorticoid Receptor Agonists or Modulators) capable of binding with receptors of GCs and thus decreasing, but not abolishing the adverse effects of GC preparations [23, 24].

For clinicians, the problem was even more difficult. GC preparations were efficient in various diseases, but not in all patients with the same disease, the effect of GCs did not depend on the level of the patients' own GCs, and it was impossible to predict efficiency of the hormonal therapy in a given patient. GC preparations caused changes in various clinical and laboratory parameters, but these changes were not specific. Thus, injection of 4 mg dexamethasone to 20 healthy male volunteers induced changes in values of 150 from 214 metabolites [25]. These difficulties led to a "natural selection" of diseases which must be treated with GC preparations. Clinical indications for prescribing GC preparations in various diseases and empirical schemes of hormonal therapy were developed within the first decades of the "GC era", and up to now, these schemes are reproduced without essential changes in numerous guidebooks, reference books, and special articles. As to adverse effects - pulse-therapy, chronotherapy, alternate-day therapy, as well as well-timed medicamentous prevention and correction of such effects are helpful for diminishing their frequency and severity.

Nevertheless, the problem of glucocorticoid therapy safety is still alive, and up to now special reviews of glucocorticoidcaused daunting complications are published [26, 27]. The 70-year-old GC therapy remains the field of clinical empirism, and up to now, clinicians are recommended to carefully compare the risk of the disease and the risk of GC therapy complications and to be guided by two major commandments:

1) GC preparations must be given considering not the diagnosis, but severity of the general condition of a patient;

2) The minimal effective dose of GC preparations must be given.

However, if it is easy to follow the first commandment, it is impossible to realize the second one, because nobody can say how to determine this "minimal effective dose".

Thus, it must be acknowledged that GC therapy of non-endocrine diseases is in a permanently critical state. May be, it is reasonable not to struggle against the hormonal properties of GC preparations, but try to use them? 
Consider briefly features of GC hormones.

\subsection{Glucocorticoids are hormones of homeostasis and stress}

The clinical use of GC preparations stimulated studies on functions of the hypothalamus-pituitary-adrenals (HPA) system, but attention was paid mainly to pharmacological effects of GC preparations, and physiology and metabolic effects of the natural GC hormones were somewhat neglected.

Glucocorticoid hormones (cortisol in humans and corticosterone in rodents) are synthesized in the adrenal cortex. GCs do not have specific target organs; comparable concentrations of their receptors are found in virtually all tissues and organs $[28,29]$. This ensures an extremely broad range of metabolic and physiological effects of GCs, they are necessary for normal metabolism of carbohydrates, proteins, and lipids, water and electrolytes, for supporting vascular tonus, functioning of cell membranes, and also for providing activities of other hormones. Thus, GCs are total action hormones and, therefore, play very essential, if not the decisive, role in supporting homeostasis [30-33]. Therefore, it is not surprising that adrenals are vitally important organs. Removal of the adrenals in humans and the majority of animals leads to general disorders in metabolism and, as a rule, death 5-6 days after the adrenalectomy. Injection of GCs rapidly improves the condition and prevents the post-adrenalectomy death; however, injection of GCs to healthy animals and humans does not improve their condition and working capacity.

GCs are synthesized in the adrenal cortex on the structural base of cholesterol molecule, and their synthesis is regulated by the adrenocorticotropic hormone (ACTH) of the pituitary by the negative feedback mechanism. In its turn, the ACTH synthesis in the pituitary is controlled similarly by the releasing factor of the hypothalamus. GC therapy increases the blood level of GCs and disturbs this regulatory mechanism in the HPA system that leads to suppression of GCs synthesis in the adrenals and adrenal failure which is a dangerous side effect of GC therapy.

In addition to supporting homeostasis at physiological rest, GCs play an extremely important role in situations which require physical and/or mental efforts, under stress conditions, and in diseases caused by different agents (bacteria, rickettsia, viruses). In such situations, the secretion of GCs by the adrenal cortex increases and their blood level can be tenfold higher than at rest [34,35]. GCs are accumulated in the focus of inflammation or a local trauma [36]. Blood levels of GCs increase in athletes during competitions, but their sportive results do not correlate with the increase in the level of their GC hormones [37]. Moreover, up to now it is not clear whether the increased secretion of GCs under stress situations or in disease compensates an increased energy demand of the body or moderates an excessive inflammation [11], but a long-term retention of the increased level of GCs leads to pathology.

However, experimental data have shown that there is a certain optimum of the adrenal cortex activity and GC provision in disease (or in stress situation). Thus, upon injection of adrenalectomized mice with a virulent Pneumococcus the optimal survival was recorded in the group of animals injected with hydrocortisone in the dose reproducing the production of corticosterone in the non-operated infected animals [38]. Similar results were obtained on adrenalectomized mice infected with Trypanosoma lewisi [39]. The existence of an optimal dose of cortisone (1 mg cortisone two times a week) was also shown on different strains of mice infected with Pneumocystis carinii - at the higher doses bacterial superinfections were observed [40]. These results make us to remind the clinical commandment to prescribe "the minimal effective dose of GC preparations".

However, in the above-mentioned experiments the researchers were dealing with linear animals which displayed identical physiological and biochemical responses. For extremely different humans, it is impossible to determine such an ideal response based on the level of glucocorticoids under various conditions. Thus, under conditions of physiological rest, cortisol concentration in blood plasma of healthy humans is $277.9 \pm 18.7 \mathrm{nM}$ (from 132 to $428 \mathrm{nM}$ ), in patients with Addison's disease it is $120.6 \pm 17.1 \mathrm{nM}$, and in the light form of Cushing disease it is $336 \pm 17.3 \mathrm{nM}$ [41]. The functional resource of the HPA system can be assessed by measurement of GCs secretion for $24 \mathrm{~h}$ before and after injection of ACTH - and it varies from 6.3 to $28.6 \mathrm{mg}$ in healthy humans under conditions of physiological rest [42]. Moreover, on the background of GC therapy such determinations are unreasonable.

A parameter is required that would be of help for determination of the "minimal effective" or the "optimal" dose.

\subsection{Hepatic tyrosine aminotransferase and blood tyrosine}

GC preparations are different from all anti-inflammatory agents by their hormonal features, i.e. by their ability to regulate metabolic reactions and physiological processes. This is realized mainly through regulation of enzyme activities. 
The action of GC hormones on enzymes was detected in the 1950s. It was shown that injection to rats of cortisone or hydrocortisone led to activation of two hepatic enzymes: tryptophan oxygenase (EC 1.13.1.12) and tyrosine aminotransferase (TAT) (EC 2.6.1.5) which catalyzed, respectively, the first stages of tryptophan and tyrosine oxidation, and this activation was especially pronounced in adrenalectomized animals. Both enzymes could be activated also by injection of the corresponding substrates, but for activation of TAT GCs also were required. The GC-dependent activation of hepatic TAT was due to de novo synthesis of the enzyme, with the maximum of 4-5 h after the injection of GCs. It should be noted that TAT is an adaptive enzyme, i.e. its synthesis corresponds to the amount of substrate - tyrosine [43, 44]. GCs increased or suppressed synthesis of many enzymes in various tissues and organs [45-49], but synthesis of the hepatic TAT was the most pronounced example of GC action on metabolism (Fig. 1) (from [50]).

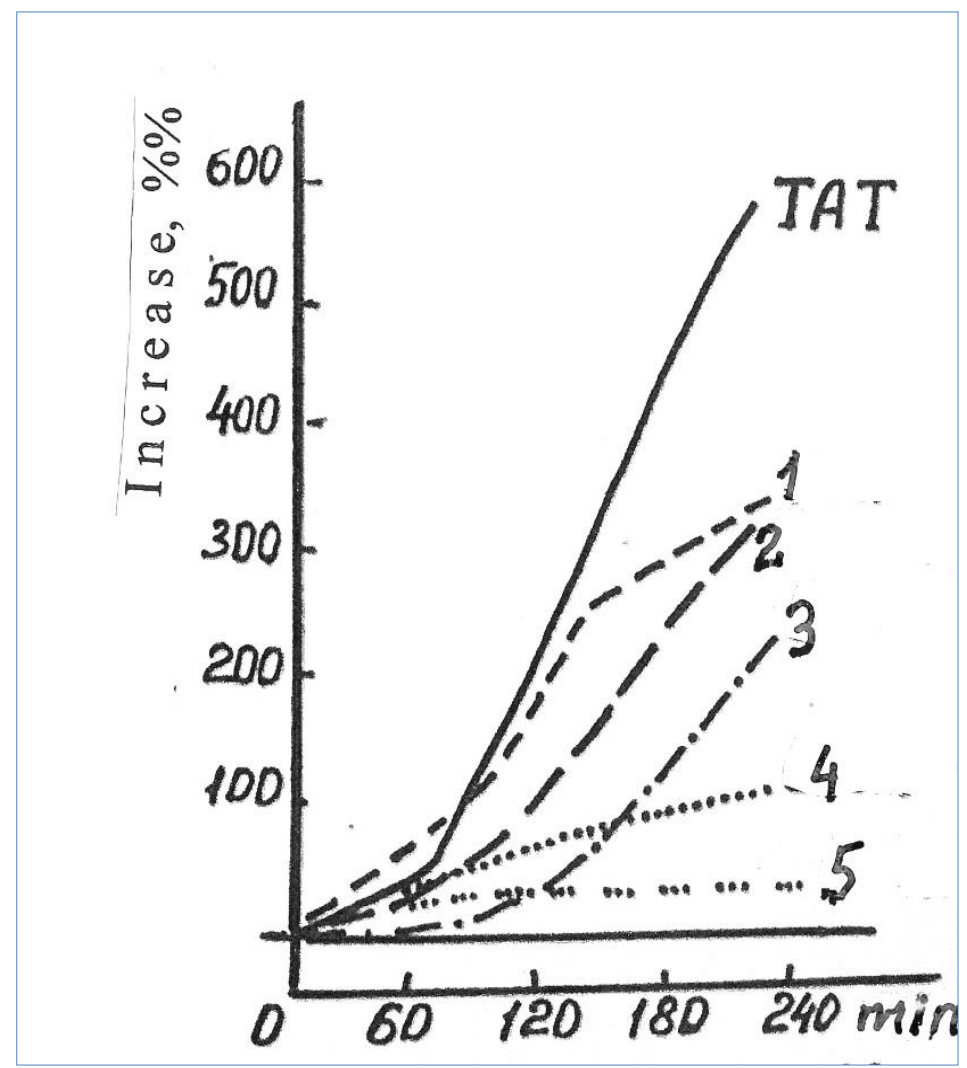

Figure 1 Changes in some hepatic and blood parameters in adrenalectomized rats after injection of cortisol (10 mg/kg body weight). 1) Hepatic adenine, 2) Hepatic tryptophan oxygenase, 3) Hepatic glycogen, 4) Blood glucose, 5) Hepatic protein. From the work [50].

Binding of GC preparations with GC receptors correlated with TAT synthesis in the rat culture hepatoma and in the rat liver in vivo, as well as with manifestations of some hormonal features: death of lymphocytes in the lymphoma culture, decrease in glucose oxidation in the tissues, suppression of the amino acid transport across the hepatocyte membrane, etc. Activities of human and animal hepatic TAT depended on GCs similarly, and in a certain range of GC concentrations the TAT activity in the cell culture or in the liver of adrenalectomized animals is proportional to amount of the injected GC [51-55].

GCs activate transcription of the hepatic TAT gene, and TAT was used as a model system for comparison of effects of hormonal preparations and natural hormones [56-59]. TAT was used also for testing newly synthesized GC preparations on cell cultures and in the liver of adrenalectomized animals [16, 17]. Thus, really, the hepatic TAT in various systems was used as an index of GC action on metabolism.

However, the hepatic TAT is the tissue enzyme and cannot be measured in blood that prevents its using as a parameter of GC action in clinical practice. But TAT is involved in metabolism of tyrosine, therefore, consider metabolism of this amino acid (Fig. 2). 


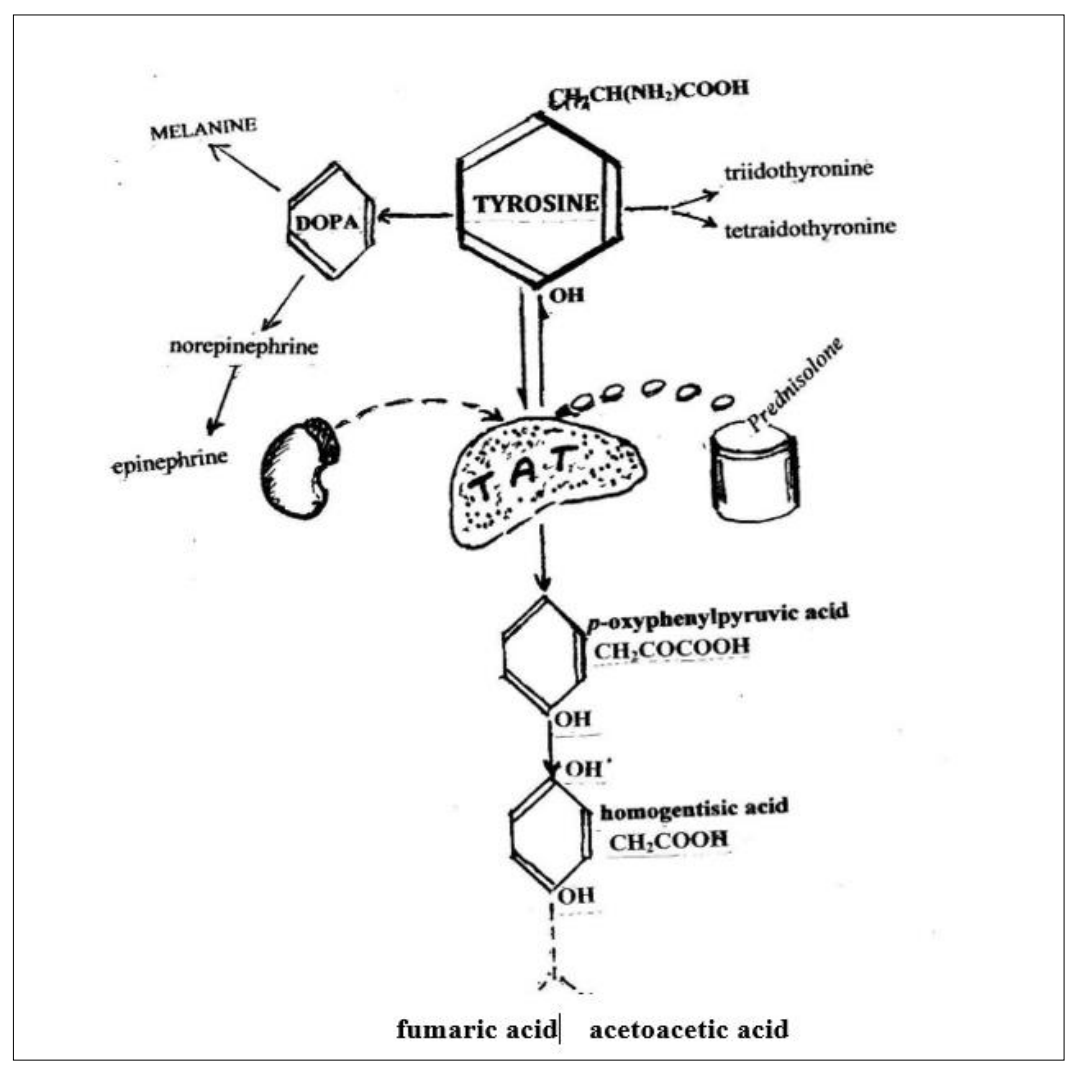

Figure 2 Tyrosine metabolism

Tyrosine is produced in the body as a result of hydrolysis of food protein immediately or after hydrolysis of phenylalanine. About $30 \%$ of the resulting tyrosine is used for synthesis of catecholamines, melanin, and thyroid hormones; a portion is used for renewal of tissue proteins, and about $60 \%$ goes by the major oxidation pathway. TAT catalyzes the first reaction in this quantitatively major oxidation pathway of tyrosine, its transamination with alphaketoglutaric acid that results in production of $p$-oxyphenylpyruvic acid ( $p$ OPP). $p$-OPP is oxidized under influence of the appropriate oxidase in the presence of ascorbic acid with production of 2,5-dioxyphenylpyruvic, or homogentisic, acid which is oxidized to 4-maleylacetic acid. The terminal products of the major pathway of tyrosine oxidation are fumaric and acetoacetic acids $[43,60,61]$ (Fig. 2).

Since TAT is an adaptive enzyme, at the functionally competent hepatocytes the synthesis of TAT will be determined by entrance of GCs into the liver, and at the sufficient amount of GCs the blood level of tyrosine is more or less constant. Really, under conditions of physiological rest, in the absence of extreme fluctuations in the diet, and on determination on the empty stomach in the morning, the levels of free tyrosine in blood are similar in healthy humans and do not depend on age and sex (Table 1). (I do not consider relatively rare congenital disorders in tyrosine metabolism caused by mutations in different enzymes involved in the metabolism of this amino acid).

Table 1 Blood tyrosine levels in humans (after [62])

\begin{tabular}{|l|l|l|}
\hline Subjects under study & The number of subjects & $\begin{array}{l}\text { Tyrosine, concentration } \\
\boldsymbol{\mu g} / \mathbf{m l}\end{array}$ \\
\hline Men & 91 & $13.0 \pm 2.7$ \\
\hline Women & 103 & $12.3 \pm 2.4$ \\
\hline Boys 6-18 yr & 75 & $12.3 \pm 1.8$ \\
\hline Girls 6-18 yr & 65 & $11.4 \pm 2.0$ \\
\hline
\end{tabular}


Similar values of blood tyrosine were obtained also by other authors in humans $[63,64]$ and in animals (rats, rabbits) [64]. Moreover, blood tyrosine level retained its individual values at repeated measurements in 61 subjects during four years [65].

Injection of GC preparations induced a dose-dependent decrease in blood tyrosine in both animals and humans, and this decrease was the most pronounced 5-6 h after the injection, i.e. at the maximum of the GC-induced synthesis of TAT. In healthy volunteers, hydrocortisone caused changes in the blood tyrosine levels and in the peripheral lymphocyte counts $[63,66-68]$. A decrease in blood tyrosine level was recorded under stress conditions [69], apparently due to the stressinduced increase in production of GCs by the adrenal cortex [70].

But what could cause an increase in the blood tyrosine level?

Because TAT was synthesized by hepatocytes, it was reasonable to expect an increase in blood tyrosine level in diseases of the liver. And really, the two-threefold increased tyrosine level was found in blood of patients with acute hepatitis and cirrhosis $[71,72]$. Injections of hepatotoxins caused in rats an increase in the blood tyrosine level, and the more pronounced was the liver necrosis, the higher was this increase [73].

In the late 1950s, Japanese researchers found increased levels of tyrosine in blood and urine of patients with collagen diseases and supposed that disorders in metabolism of this amino acid could be a biochemical basis of these pathologies $[74,75]$. These findings stimulated many studies on tyrosine metabolism in various diseases, and during some next years, an increase in blood tyrosine levels was recorded in patients with acute leukemia, acute pneumonia, acute peritonitis, rheumatism, and collagenoses without the pronounced liver damage in the majority of cases. Hypertyrosinemia in these cases apparently did not contribute to pathogenesis of the diseases under study, and the authors did not continue their studies.

However, some Russian researchers observed that the increase in blood tyrosine level correlated with activity of rheumatism and that blood tyrosine became normal at the successful hormonal and medicamentous therapy; moreover, withdrawal of GCs in some patients was associated with increase in blood tyrosine (64, 76-78], but neither of these authors tried to elucidate the cause of this obviously nonspecific increase in blood tyrosine level.

Nevertheless, disorders in tyrosine metabolism seemed to be the simplest approach to the problem of systemic lupus erythematosus (SLE) which I was proposed to study when I became a researcher at the Clinic of Therapy and Occupational Diseases, I Moscow Medical Institute. Thus, in 1970, I started measurements of blood tyrosine in patients with SLE, and after they were discharged from the Clinic, I compared my measurements of their blood tyrosine with their case histories. This comparison allowed me to suppose that blood tyrosine level could be considered an index of GC action on metabolism and of tissue provision with these hormones (or preparations) [79, 80]. The purpose of my further studies was to prove this hypothesis experimentally and on other clinical models - I shall refer to these publications in the due place.

In this article, I shall present the results of those 40-year-old studies beginning from the most demonstrative example of blood tyrosine dependence on GCs - adrenalectomy of rats.

\section{Blood tyrosine behavior versus glucocorticoids}

In the following researches, the main laboratory approach was measurement of blood tyrosine level by the method of Udenfriend and Cooper [81].

To $1 \mathrm{ml}$ of blood serum, $3 \mathrm{ml}$ of water and $1 \mathrm{ml}$ of $30 \%$ trichloroacetic acid were added; protein was precipitated by centrifugation at $3000 \mathrm{rpm}$ for $10 \mathrm{~min}$. To $2 \mathrm{ml}$ of the supernatant $1 \mathrm{ml}$ of $0.1 \%$ 1-nitroso-2-naphthol solution in $96 \%$ ethanol and $1 \mathrm{ml}$ of $0.05 \%$ sodium nitrite solution in $20 \%$ nitrogen acid were added that resulted in formation of a stained complex with tyrosine. After incubation at $55^{\circ} \mathrm{C}$ for $30 \mathrm{~min}$, the excess of the dye was extracted with $10 \mathrm{ml}$ dichloroethane (or chloroform), and the extinction of the aqueous phase was determined at $450 \mathrm{~nm}$ with a spectrophotometer. For the reference sample, distilled water was used.

For control, blood tyrosine was measured in blood of 16 healthy donors. 


\subsection{Blood tyrosine behavior in adrenalectomized rats}

Removal of adrenals does not result in the death of all rats due to presence of the brown fat tissue, or additional adrenals [82]. However, some disorders are observed, e.g. a decrease in the body weight, disorders in the salt metabolism, etc., which are the most pronounced 4-5 days after the adrenalectomy [67].

According to the work [83], blood corticosterone level in intact rats was $19.0 \pm 1.4 \mu \mathrm{g} / 100 \mathrm{ml}$, after bilateral adrenalectomy it fell, became undeterminable four days after the operation and appeared on the $7^{\text {th }}$ day - to $5.9 \mu \mathrm{g} / 100$ $\mathrm{ml}$ (Fig. 3,a). Similar data on changes in blood level of corticosterone after adrenalectomy in rats were obtained by other authors $[84,85]$ who also recorded a sharp increase in the blood level of ACTH in response to removal of the adrenals. This increase in the synthesis of ACTH also induced removal of corticosterone from its complex with transcortin [86] that resulted in a stepwise development of the hormonal tissue deficiency - with the death of some animals mainly in 5-6 days after the adrenalectomy (i.e. at the undeterminable level of corticosterone). The appearance of corticosterone on the $7^{\text {th }}$ day was caused by its synthesis in the brown fat tissue that was stimulated by the increased synthesis of ACTH [87].

In our experiment [88], young male rats Wistar with the body weight of 120-140 g (the age about 2.5 months) were subjected to bilateral adrenalectomy. Animals of this age were chosen because in the preliminary experiments about half of the younger operated animals died in 5 days after the adrenalectomy, whereas the operation had virtually no influence on conditions of the elder animals (judging by the increase in the body weight).

The adrenals were removed via the dorsal incision under ether anesthesia. Before the operation and during the observation period the rats received the same diet containing about $10 \%$ protein and water supplemented with sodium chloride (10 g/liter).

After the adrenalectomy, the rats were weighed, and the weight loss was maximal on the $5^{\text {th }}$ day after the operation (Table 2).

Table 2 Changes in body weight of the rats after bilateral adrenalectomy

\begin{tabular}{|c|c|c|}
\hline $\begin{array}{l}\text { Days after } \\
\text { adrenalectomy }\end{array}$ & Body weight (g) & $\begin{array}{l}\text { The number of weighed } \\
\text { animals }\end{array}$ \\
\hline 0 (before operation) & $135 \pm 1.4$ & 25 \\
\hline 2 & $129 \pm 1.6$ & 15 \\
\hline 3 & $126 \pm 4.8$ & 10 \\
\hline 5 & $125 \pm 3.2$ & 17 \\
\hline 7 & $141 \pm 4.6$ & 6 \\
\hline 10 & $152 \pm 4.6$ & 6 \\
\hline $15-18$ & $166 \pm 6.0$ & \\
\hline
\end{tabular}

Blood samples were taken by cutting the tip of the rats' tail in the morning, directly before the operation, and then on the $3^{\text {rd }}, 5^{\text {th }}, 7^{\text {th }}, 10^{\text {th }}$, and $15^{\text {th }}-18^{\text {th }}$ days after the adrenalectomy. During the experiment, the same animals were under study, therefore, the blood samples were taken from different rats. The serum was diluted twofold to obtain $1 \mathrm{ml}$ for determination of tyrosine as described in [81].

Changes in blood levels of corticosterone (from the work [83]) and the results of tyrosine measurements in the adrenalectomized rats [88] are presented in Fig. 3,a. One can see that after the operation blood tyrosine level increased and reached the maximum on the $5^{\text {th }}$ day that corresponded to the most pronounced weight loss (Table 2 ) and the death of $15-20 \%$ of the operated animals in different series of the experiment. Thus, the blood tyrosine maximum corresponded to the minimum of own corticosteroids and to critical conditions of the animals after the adrenalectomy. In the survived rats, blood tyrosine level began to decrease and became normal on the $10^{\text {th }}$ day after the operation, apparently due to activation of corticosterone synthesis in the brown fat tissue (Fig. 3,a). The body weight of the operated rats also began to increase, and by the $10^{\text {th }}$ day they had the same weight as the non-operated animals of the party. 
It was interesting also to follow changes in the blood tyrosine level in adrenalectomized rats in response to injection of GC preparation. Starting from the $7^{\text {th }}$ day after the adrenalectomy, 10 adrenalectomized rats were injected intraperitoneally with hydrocortisone in the dose of $2 \mathrm{mg} / \mathrm{kg}$ body weight per day. This dose approximately corresponded to the supporting dose of $15 \mathrm{mg}$ prednisolone in humans. Hydrocortisone preparation was diluted with saline to obtain the volume of $0.3-0.4 \mathrm{ml}$ for the intraperitoneal injection, and they were performed in the morning. Hydrocortisone was injected daily for 20 days, withdrawn for 5 days, and then three injections of hydrocortisone $(5$ $\mathrm{mg} / \mathrm{kg}$ body weight) were performed (Fig. $3, b$ ).

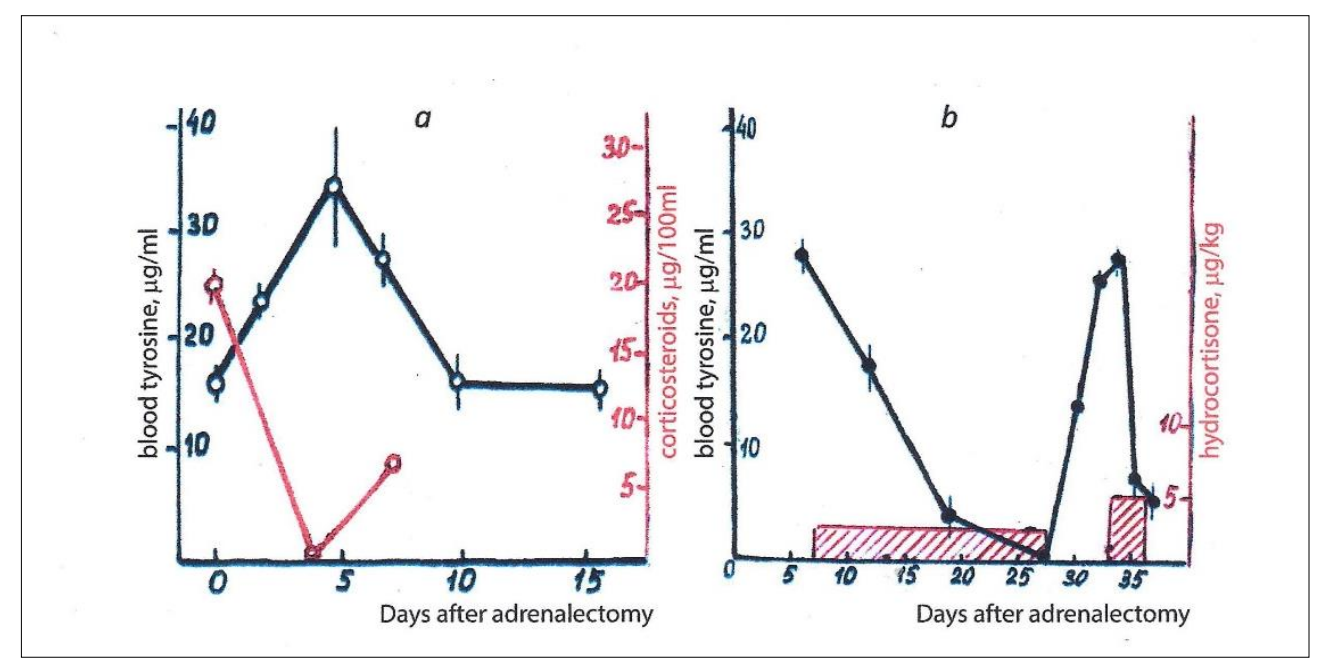

Figure $3 a$ ) Changes in blood level of endogenous corticosteroid hormones (red curve, the data from [83]) and of tyrosine (black curve) in the rats after bilateral adrenalectomy. $b$ ) Changes in blood level of tyrosine (black curve) in the adrenalectomized rats subjected to daily injections of hydrocortisone ( $2 \mathrm{mg} / \mathrm{kg}$, red hatched), upon withdrawal of these injections, and on the recommencement of hydrocortisone injections in the dose of $5 \mathrm{mg} / \mathrm{kg}$.

Thus, in the model of adrenalectomy in rats blood tyrosine behavior clearly depended on delivery into the tissues of GCs, both endogenous (Fig. 3,a) and exogenous (Fig. 3,b).

\subsection{Blood tyrosine level in glucocorticoid replacement therapy}

It was reasonable also to compare blood tyrosine level in patients with adrenal cortex pathology receiving a replacement GC therapy. Such study was performed in the Institute of Experimental Endocrinology and Chemistry of Hormones (IEECH) together with Prof. M.A. Zhukowsky and Dr. E.S. Kuznetsova [89].

It is obvious that patients with adrenal insufficiency need GC replacement therapy. Nevertheless, the physiological replacement of GCs presents a difficult challenge: it is not easy to determine exactly, "How much is enough" is unclear [90]. The difficulties are associated with broad variations in the normal levels of GC hormones and rapid changes in their level in response to various stimuli and under different situations [41]. There is no laboratory parameter which would allow endocrinologists to assess whether the GC dose at the replacement therapy was adequate to real needs of a patient with adrenal insufficiency, moreover, even to detect this condition is difficult in some cases.

The problem is somewhat easier in children with congenital adrenal hyperplasia (CAH), or adrenogenital syndrome. In the adrenal cortex not only glucocorticoids and mineralocorticoids are synthesized from cholesterol, but also C-19 compounds possessing the androgenous activity. Most frequently, CAH is caused by the inborn deficiency of the enzyme 21-hydroxylase responsible for biosynthesis of cortisol, and this results in the shift to synthesis of androgens (mainly dehydroepiandrosterone). The reduced production of GCs leads to a persistent stimulation of the pituitary gland and the increased synthesis of ACTH. ACTH stimulates the adrenal cortex, and the surplus androgens are synthesized repeatedly instead of cortisol because of the genetic defect.

The excess of androgens manifests itself by a specific clinical picture: an abnormal structure of external sex organs, accelerated growth during the first years of life, and the early termination of growth because of premature ossification of growth zones in the tubular bones. In the affected girls a picture of pseudohermaphroditism develops: the masculine type of muscles and pilosis, and absence of the secondary sex traits (at the presence of ovaries and uterus). In the affected boys, there is a premature sex development [91-93]. 
In $\mathrm{CAH}, \mathrm{GC}$ preparations must be given to an affected baby as early as possible and be taken lifelong. GC preparations break the vicious cycle: the normal level of GCs in blood prevents the excess synthesis of ACTH, the ACTH-caused stimulation of the adrenal cortex, and the resulting overproduction of androgens. The dose of GCs must be corrected regularly and strictly individualized based on the rate and character of the growth and sex maturation - usually once a half-year. The correct replacement therapy allows endocrinologists to obtain in the affected girls the normal pregnancy and childbirth [94]. At the prescribing and correcting the dose of GC preparations, the endocrinologist should balance between their insufficient and excessive dose, i.e. between the hyperandrogenism and hypercorticism [95-97].

However, $\mathrm{CAH}$ in children seems to be the only clinical situation when a physician can more or less objectively assess the adequacy of the dose of GC preparations to real needs of a patient.

Our study was performed on children with CAH who were hospitalized into the Children Department of IEECH for observation and correcting the dose of GCs if necessary. Our purpose was to compare the blood tyrosine levels with the compensation parameters, i.e. the rate of growth and sex maturation in the children with CAH. Under study there were 38 children, 33 girls and 5 boys from 3 to 18 years old. Tyrosine was determined in blood samples taken in the morning on empty stomach. The data were compared with the clinical picture. The results are presented in Fig. 4.

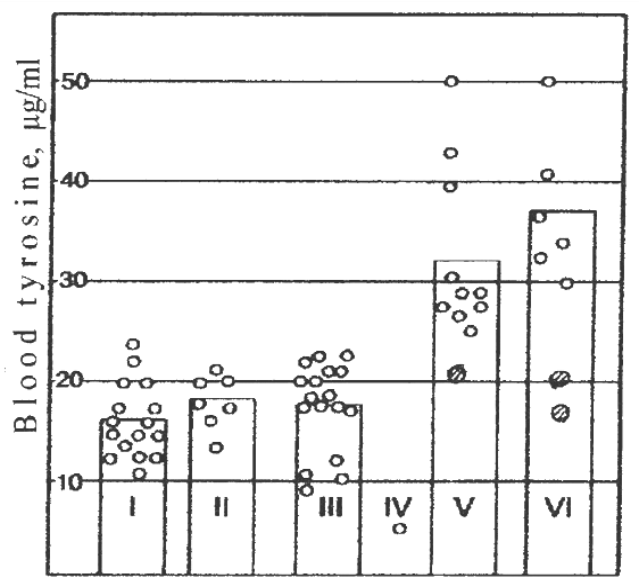

Figure 4 Tyrosine levels in blood of healthy adult donors and healthy children and of children with congenital adrenal hyperplasia. The columns present arithmetic means for the corresponding groups, the circles present individual values. I) Adult donors; II) healthy children; III) patients with CAH with a complete clinical compensation; IV) an affected girl with overdosed GCs; V) patients with CAH with incomplete compensation; VI) untreated patients with CAH. The hatched circles in the columns V and VI indicate blood tyrosine levels in patients with melanodermia (compare with Tyrosine metabolism presented in Fig. 2!).

Blood tyrosine levels were the same in 16 healthy adults $(16.2 \pm 0.9 \mu \mathrm{g} / \mathrm{ml})$ and in seven healthy children of $7-13$ years old $(17.8 \pm 1.0 \mu \mathrm{g} / \mathrm{ml}$ ) (the columns I and II, respectively). Tyrosine blood levels were also normal in children with the complete clinical compensation (the column III). In two compensated patients blood tyrosine level was increased during acute respiratory disease, and they were given an increased dose of GCs for several days (according to the empirical recommendation to increase the dose of GCs in occasional infections!). After the infection ended, blood tyrosine in these children became normal. In a 4-year-old girl with the traits of Cushing syndrome and bone age corresponding to 10 years blood tyrosine was $5.0 \mu \mathrm{g} / \mathrm{ml}$ (the column IV).

Blood tyrosine levels were significantly increased in irregularly treated patients with incomplete compensation and in untreated patients (the columns V and VI). Note that normal tyrosine values were recorded in three non-compensated children (the hatched circles in the column V and VI) - these children had melanodermia. Obviously, this melanodermia was caused by conversion of a part of free tyrosine into the pigment melanin instead of taking the major pathway of tyrosine metabolism (compare with Figure 2!). The melanodermia disappeared upon prescribing GC preparations.

Thus, our observations in children with CAH receiving the replacement GC therapy showed that blood tyrosine level was a representative index of tissue provision with GCs. The normal level of blood tyrosine corresponded to normal provision of tissues with GCs, whereas an increased blood tyrosine level indicated an insufficient provision of the tissues with GCs. 
Determination of blood tyrosine level has not only a "scientific interest" as an index of tissue provision with GCs, but it can be of help for prescribing and correcting the dose of the substitutive GC preparations. Figure 5 exemplifies an untreated girl who was prescribed GC preparations, and values of blood tyrosine helped the pediatrician to choose the adequate dose. The optimal dose could be chosen within two weeks and it could be "titrated" very accurately.

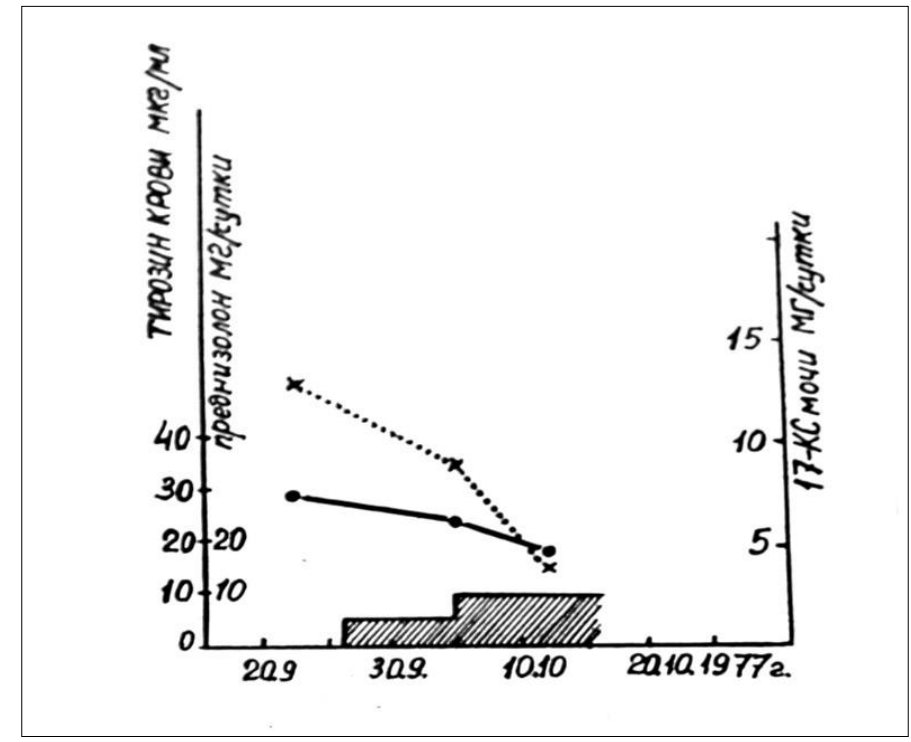

Figure 5 Blood tyrosine level $(\bullet \bullet)$, urinary excretion of 17-ketosteroids $(\times \cdots \times)$, and prednisolone (hatched) in an untreated 4-year-old girl with $\mathrm{CAH}$, with the bone age corresponding to 10 years. 17-Ketosteroids are urinary products of androgens and are used for approximate determination of the dose of GCs. But as a urinary parameter, it also depends on food components. Blood tyrosine level is more reliable.

In other cases of adrenal insufficiency, e.g., hypopituitarism and Addison's disease, it is difficult to reveal this condition in the absence of melanodermia, and there are no characteristics of the adequacy of the GC replacement therapy [98]. The only orientation is the average level of GC hormones in healthy people and a patient's feeling, but, obviously, both these "reference points" are rather conventional (compare with data presented in 2.2 [41]).

However, I would like to present here our unpublished observation with Dr. T.A. Okeanova from the same Institute on an adult patient with Addison's disease (Table 3).

Table 3 Blood tyrosine level, skin pigmentation, and GC preparations in a patient with Addison's disease

\begin{tabular}{|l|l|l|l|}
\hline Date & GC therapy & Skin condition & Blood tyrosine $\boldsymbol{\mu g} / \mathbf{m l}$ \\
\hline 13.06 .1977 & Without therapy & Skin hyperpigmentation & 18.5 \\
\hline 17.06 .1977 & Prednisolone, $10 \mathrm{mg} \times 3$ days & Skin whitening & 46.0 \\
\hline 01.07 .1977 & Stopped taking prednisolone & Skin darkening & 12.0 \\
\hline .11 .1977 & No prednisolone & Skin hyperpigmentation & 17.0 \\
\hline
\end{tabular}

Possibly, this patient was adapted to her condition, and the dose of $10 \mathrm{mg}$ prednisolone per day was too high for her and unpleasant.

It should be noted that the hormone-dependent skin whitening was described in the literature [99], but without reference to tyrosine metabolism.

It is interesting to mention the work by Christiansen et al. [100]: the authors assessed the effect of acute withdrawal of cortisol on many metabolic parameters in seven patients with Addison's disease. In particular, the levels of amino acids were determined. It occurred that $24 \mathrm{~h}$ after withdrawal of the replacement therapy (hydrocortisone + fluorocortisone) 
a significant increase $(33 \%, \mathrm{p}<0.005)$ was recorded only of tyrosine (the next significant increase was recorded for alanine $(16 \%, \mathrm{p}<0.02)$. (Compare with Fig. 1!)

Thus, blood tyrosine level seems to be the most sensitive index of tissue provision with glucocorticoids.

\subsection{Adrenal cortex activity and blood tyrosine in patients with bronchial asthma}

Bronchial asthma is a chronic disease with the clinical picture characterized by asphyxia attacks caused by bronchospasm, hypersecretion of mucosa, and edema of the bronchi. Asthma is the most frequent chronic inflammatory disease of the respiratory system, with an estimated 300 million cases worldwide [101]. Administration of GC preparations in bronchial asthma (BA) was started in the Mayo Clinic immediately after the first use of cortisone [4].

In $\mathrm{BA}, \mathrm{GC}$ preparations are the most effective drugs and up to now retain the central role as inhaled and systemic preparations in the therapy of BA; they are life-saving in status asthmaticus and in severe attacks of BA. In addition to the general anti-inflammatory action, GC abolish spasm of the smooth muscles and recover the drainage function of bronchi. In some patients with BA, GC preparations are used as supporting drugs [102-106].

Since adrenal insufficiency is one of the most serious complications of GC therapy and can cause death under occasional stress situations, functions of the hypothalamus-pituitary-adrenal (HPA) system in patients with BA were under study in many works [107-110]. At the suppressed adrenocortical functions, stress situations can provoke bronchospasm that can be abolished by GC preparations [111, 112].

For assessment of functions of the HPA system, blood cortisol levels are determined before and after provocative injections of ACTH or its analogs; that makes it possible to assess resources of the HPA system. As a rule, in the state of clinical remission parameters of the HPA system are in normal limits.

During exacerbations of BA, no correlation was found between severity of the clinical picture and the parameters of the HPA system activity; in particular, in status asthmaticus the blood level of cortisol varied from 2.7 to $50 \mu \mathrm{g} / 100 \mathrm{ml}$ [107]. GC preparations are efficient in the majority of patients with BA, independently of the level of their own GC hormones and of their responses to provocative tests. This promoted an appearance of the idea about "purely pharmacological action of GC preparations in BA" as anti-inflammatory, anti-allergic, and spasmolytic drugs" which can specifically and rapidly improve functions of the lungs and bronchi.

It was assumed that determination of blood tyrosine level as an index of tissue provision with GCs would be useful for the more comprehensive evaluation of the adrenocortical activity in patients with BA.

Table 4 Blood levels of tyrosine, 11-oxycorticosteroids (total and biologically active) and cortisol (total and biologically active) $(\mathrm{M} \pm \mathrm{m})$ in patients with bronchial asthma in the state of remission and of exacerbation.

\begin{tabular}{|l|l|l|l|l|l|l|}
\hline $\begin{array}{l}\text { Group under } \\
\text { study }\end{array}$ & $\boldsymbol{n}$ & $\begin{array}{l}\text { Tyrosine } \\
\boldsymbol{\mu g} / \mathbf{m l}\end{array}$ & $\begin{array}{l}\mathbf{1 1 - 0 X}, \text { total } \\
\boldsymbol{\mu g} / \mathbf{1 0 0} \mathbf{~ m l}\end{array}$ & $\begin{array}{l}\mathbf{1 1 - 0 X} \text { active } \\
\boldsymbol{\mu g} / \mathbf{1 0 0} \mathbf{~ m l}\end{array}$ & $\begin{array}{l}\text { Cortisol, total } \\
\boldsymbol{\mu g} / \mathbf{1 0 0} \mathbf{~ m l}\end{array}$ & $\begin{array}{l}\text { Cortisol, } \\
\mathbf{a c t i v e} \\
\boldsymbol{\mu g} / \mathbf{1 0 0} \mathbf{~ m l}\end{array}$ \\
\hline Donors & 16 & $16.9 \pm 0.9$ & $17.4 \pm 1.5$ & $1.9 \pm 0.4$ & $14.2 \pm 1.0$ & $1.9 \pm 0.1$ \\
\hline $\begin{array}{l}\text { Patients in } \\
\text { remission }\end{array}$ & 10 & $17.3 \pm 2.7$ & $\begin{array}{l}22.6 \pm 2.0 \\
p<0.05\end{array}$ & $\begin{array}{l}4.7 \pm 0.6 \\
p<0.01\end{array}$ & $14.1 \pm 1.7$ & $2.1 \pm 0.6$ \\
\hline $\begin{array}{l}\text { Patients in } \\
\text { exacerbation }\end{array}$ & 15 & $\begin{array}{l}\mathbf{4 0 . 3}+\mathbf{2 . 9} \\
\boldsymbol{p}<\mathbf{0 . 0 1}\end{array}$ & $18.2 \pm 2.0$ & $\begin{array}{l}3.7 \pm 0.5 \\
p<0.05\end{array}$ & $\begin{array}{l}12.4 \pm 1.6 \\
p>0.05\end{array}$ & $\begin{array}{l}2.6 \pm 0.4 \\
p>0.05\end{array}$ \\
\hline
\end{tabular}

The work was performed at the Clinic of Therapy and Occupational Diseases together with clinicians [113]. Thirty patients with BA, 24 women and 6 men in the age from 20 to 69 years old, were under study. Fifteen patients had frequent lingering attacks and their state was characterized as exacerbation, 11 patients were in the state of remission without attacks, four patients had rare short-time asphyxia attacks and their condition was characterized as a relative remission. During the study and immediately before the hospitalization the patients did not receive hormonal preparations. Blood samples were taken in the morning on the empty stomach and tyrosine, and corticosteroids (11oxycorticosteroids and cortisol, total and biologically active) were determined in the same blood sample (tyrosine as described in [81], the hormones were determined as described in [114]. 
The results of the measurements are presented in the Table 4.

Table 4 shows that in the patients in the state of remission and exacerbation the average values of 11-OX and cortisol, total and biologically active, were either in normal limits or slightly increased.

The results of blood tyrosine measurement were more interesting: in 16 healthy donors it was, on average $16.2 \pm 0.9$ $\mu \mathrm{g} / \mathrm{ml}$ (from 11.2 to $23.7 \mu \mathrm{g} / \mathrm{ml}$ ) and in 10 patients in remission it was, on average, virtually the same, $17.3 \pm 2.7 \mu \mathrm{g} / \mathrm{ml}$, but with wider range of the values (from 2.5 to $26.5 \mu \mathrm{g} / \mathrm{ml}$ ). At the state of relative remission blood tyrosine was normal in two patients (11.0 and $12.5 \mu \mathrm{g} / \mathrm{ml})$ and increased in two patients $(30.5$ and $42.0 \mu \mathrm{g} / \mathrm{ml})$. In a patient in remission with alcohol-caused damage of the liver blood tyrosine was $43.5 \mu \mathrm{g} / \mathrm{m}$.

In all 15 patients in the state of exacerbation blood tyrosine levels were increased, from 27.5 to $68.5 \mu \mathrm{g} / \mathrm{ml}$, on average, $40.3 \pm 2.9 \mu \mathrm{g} / \mathrm{ml}$, i.e. significantly higher than in the patients in remission and in the donors.

Thus, in the patients with BA in the state of exacerbation with more or less normal blood levels of adrenocortical hormones, blood tyrosine level was increased, i.e. the tissue provision with GCs was insufficient, and apparently just this insufficiency is an explanation of the GCs efficiency in BA.

The clinicians (B..A. Kornev and T.A. Turusina [113]) paid attention to a patient in a relative remission: at the first determination her blood tyrosine was $1.10 \mu \mathrm{g} / \mathrm{ml}$, but about a year later her condition became worse, and blood tyrosine increased to $3.05 \mu \mathrm{g} / \mathrm{ml}$, whereas the level of 11-OX was unchanged. The clinicians noticed that this increase in blood tyrosine could be considered a signal for prescribing a small dose of GCs (or another preparation) to prevent the further worsening.

Thus, the determination of blood tyrosine level in bronchial asthma made it possible to characterize the functional activity of the HPA system more completely because it reveals the tissue provision with GC hormones and its sufficiency to real requirements of the patient. It is very important that blood tyrosine can be determined on the background of GC therapy.

\subsection{Blood tyrosine behavior and glucocorticoid therapy in systemic lupus erythematosus}

Systemic lupus erythematosus (SLE) is a systemic inflammatory disease of the connective tissue affecting virtually all organs: joints, kidneys, serous membranes, lungs, gastrointestinal tract, cardiovascular system, blood system, central nervous system. SLE is also a typical autoimmune disease with a multiplicity of auto-antibodies: to DNA, to blood cells, to the basal membrane of different organs. In the stroma of various organs immune complexes are found, some of which serve a diagnostic trait ("lupus cells") [115]. SLE strike mainly young women (6-9 women against 1 man). Before introduction of GC preparations in clinical practice, the majority of the affected women died within three years.

SLE is the most impressive example of using GC preparations in non-endocrine diseases when all features of these drugs are realized: GCs act as the most powerful anti-inflammatory, anti-allergic, and immunosuppressive agents [116-120].

Currently, in the treatment of SLE GCs are usually combined with various other preparations (antimalarial, immunosuppressive, and non-steroidal anti-inflammatory drugs). In addition to their own therapeutic effects, these preparations allow the therapists to decrease the dose of GCs. In SLE, high doses of GCs are given at generalization of the process and in exacerbations, and decreasing the dose of GCs usually begins on appearance of the signs of Cushing syndrome. Moreover, the majority of SLE patients usually receive low "supporting" doses of GCs for a long time or even lifelong. In any case, GC preparations remain the cornerstone in the schemes of SLE treatment [121-123], and all problems associated with the administration of GCs still exist: nearly inevitable serious side effects, a difficulty and sometimes an impossibility to abolish GCs, resistance of some patients to GC therapy. Such was the situation in the beginning of the "steroid era" and nowadays the same problems are still alive. In 2013, Luijten et al. [124] acknowledge that after 60 years the use of GCs in SLE was still more an art than science. In 2017, clinicians had to admit that the problem of GCs in lupus had not gone away and the risk/benefit ratio was persistent $[125,126]$.

To specify and refine approaches for using GC preparations in SLE and find out specific indications for GC therapy, there were attempts to establish a relation between the efficiency of GCs with different individual characteristics of the patients, such as the number and type of GC receptors [127], antibodies to double-stranded DNA [128], specific features of T- and B-cells $[129,130]$, immune functions of neutrophils [131]. These characteristics are thought to be more or less associated with pathogenesis of SLE, but neither of them helps in predicting the efficiency of GCs or in monitoring the GC therapy. 
My study on SLE was during 1970-1976. As a have mentioned earlier, disorders in tyrosine metabolism seem to me the easiest approach to the problem of SLE.

Blood samples for biochemical or immunological analyses were taken from patients with SLE more or less regularly, usually once in 7 or 14 days, and I simply took $1 \mathrm{ml}$ of serum from these blood samples. Initially I measured the level of tyrosine and $p$-oxyphenylpyruvic acid in blood and 24-h urine, but blood tyrosine values were the most informative. Therefore, in the further researches I measured only tyrosine level in blood samples of patients with SLE.

Tyrosine level in blood of 16 healthy donors ( 14 women and 2 men in the age from 20 to 40 years old) was in the range from 11.2 to $23.7 \mu \mathrm{g} / \mathrm{ml}, 16.2 \pm 0.9 \mu \mathrm{g} / \mathrm{ml}$, on average. The repeated determinations of blood tyrosine in the same donors gave virtually the same values, i.e. blood tyrosine was rather a stable individual parameter in a healthy subject. Obviously, this observation was in agreement with the literature data cited in 2.3.

During the period of 1973-1976 altogether 80 patients with SLE, 70 women and 10 men in the age from 16 to 53 years old, were observed at 134 hospitalizations. The patients were not chosen based on the severity and character of the disease and they were treated as it was adopted in the Clinic; patients with a very severe damage of kidneys were not included in this study. Blood tyrosine levels in the patients with SLE varied from 13.7 to $160 \mu \mathrm{g} / \mathrm{ml}$.

After the patients' discharge from the Clinic, I compared changes in their blood tyrosine levels with the records in their case histories: the treatment, results of laboratory analyses, procedures, commentaries on the patients' conditions', etc. I took into consideration also their previous histories, since some of the patients were hospitalized repeatedly. Such post factum processing of the data may be called a "retrospective experiment".

Thirty-six patients with SLE were observed in the state of clinical remission; blood tyrosine was in normal limits in 23 of them and was steadily elevated in three patients (two of them had the affected liver); 28 patients obtained a supporting dose of GCs (not more than $15 \mathrm{mg}$ prednisolone per day). Alongside with normal values of blood tyrosine, in some patients in remission 59 "jumps" of tyrosine up to 50-60 $\mathrm{gg} / \mathrm{ml}$ were recorded, and the retrospective analysis revealed that these "jumps" were associated with some extraordinary events, such as an intercurrent infection, a diagnostic procedure (e.g. kidney biopsy), an allergic reaction to a new preparation, etc. At acute respiratory infection, the blood tyrosine could increase up to $80 \mu \mathrm{g} / \mathrm{ml}$ and this high level retained during the infection. Thus, these "jumps" were associated with "stress situations" when in healthy subjects the synthesis of GC hormones should increase. Similar "jumps" were recorded also in patients with glomerulonephritis at similar situations. "Jumps" in blood tyrosine were also observed in some patients with SLE at the alternate-day scheme of GC therapy on the next morning after the GCfree day.

These "jumps" could be explained on assuming that synthesis of GC hormones under stress situations was insufficient for synthesis of the adequate amount of TAT - i.e. indicated a transient shortage of GCs. It is reasonable to remind the empirical recommendation to increase dose of GC preparations to patients on supporting hormonal therapy at occasional infections, surgery, etc.

However, the most interesting were the observations of tyrosine behavior in 32 patients with SLE who, according to the conventional schemes, were given the increased dose of GC preparations (40-60 mg/day calculated per prednisolone) because of clinical exacerbation.

Table 5 Changes in blood tyrosine level in patients with SLE upon prescribing GC preparations and results of the GC therapy course

\begin{tabular}{|c|c|c|c|c|c|}
\hline \multirow{2}{*}{$\begin{array}{l}\text { Blood tyrosine }(\mu \mathrm{g} / \mathrm{ml}) \text { at } \\
\text { prescribing GCs }\end{array}$} & \multirow{2}{*}{ Number of patients } & \multirow{2}{*}{ Improvement } & \multirow{2}{*}{$\begin{array}{l}\text { Absence } \\
\text { of effect }\end{array}$} & \multicolumn{2}{|c|}{ Changes in blood tyrosine } \\
\hline & & & & Decreasing & Unchanged \\
\hline \multirow{2}{*}{$\begin{array}{l}\text { Increased } \\
49.1 \pm 0.8\end{array}$} & \multirow{2}{*}{20} & 17 & & 13 & $4^{*}$ \\
\hline & & & 3 & & \\
\hline \multirow{2}{*}{$\begin{array}{l}\text { Within normal } \\
\text { limits } \\
(<26.5)\end{array}$} & \multirow[b]{2}{*}{12} & $3^{* *}$ & & 3 & \\
\hline & & & 9 & & $9\left(4^{* * *}\right)$ \\
\hline
\end{tabular}


The post-discharge analysis revealed that to 20 patients GCs were given on the background of the significantly increased blood tyrosine level $(49.1 \pm 0.8 \mu \mathrm{g} / \mathrm{ml})$ and an essential improvement of clinical and laboratory parameters was recorded in 17 of them. In 13 of these 17 patients this improvement was concurrent with decreasing in the blood tyrosine level, and the blood tyrosine became normal before appearance of Cushing syndrome signs indicating an overdose of GC preparations and considered a signal for decreasing the dose of GCs. In four patients with the markedly affected liver functions, blood tyrosine remained elevated, although their general conditions became better. Note that the "improvement" in all cases concerned only the SLE activity and the side effects were considered inevitable.

Twelve patients with SLE were given GCs on the background of normal level of blood tyrosine $(<26.5 \mu \mathrm{g} / \mathrm{ml})$. GCs were inefficient in nine of them, and in four patients signs of Cushing syndrome appeared very rapidly. Some improvement was recorded in three patients, but it could be due to other preparations given concurrently with GC preparations: azathioprine, heparin, cyclophosphamide, etc.

These observations are summarized in Table 5.

Thus, GC preparations were favorable when they were given on the background of the increased blood tyrosine, i.e. at the insufficient hormonal provision and until the normalization of the blood tyrosine level, i.e. the reaching normal tissue provision. GC preparations were unsuccessful when they were given on the background of normal blood tyrosine, i.e. at the sufficient hormonal provision that rapidly resulted in the side effects.

GC preparations were favorable when and until they compensated the tissue insufficiency. The minimal efficient dose was the dose compensating the tissue insufficiency manifested by the increased blood tyrosine.

The therapeutic effect of GC preparations in SLE was concurrent with their regulatory action on tyrosine metabolism. Thus, it would be reasonable to use determination of blood tyrosine for prescribing and especially for monitoring GC therapy (taking into account the liver functional competence).

The results of this work were published [79] in co-authorship with the clinicians (I.A. Borisov, T.A. Nikishova, and V.V. Sura) who treated the patients in the Clinic.

I would like to present a case of SLE when using blood tyrosine as a laboratory parameter would possibly allow to prevent the tragic results of GC therapy (Fig. 6).

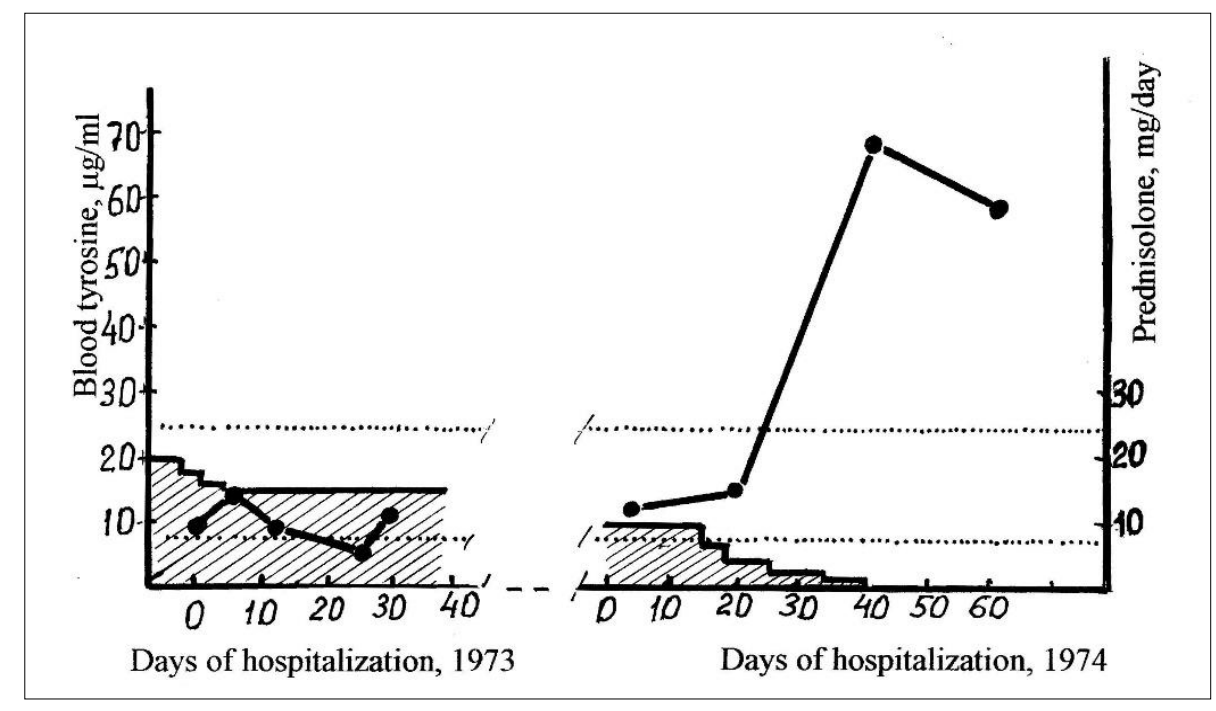

Figure 6 Blood tyrosine behavior (the black curve) at withdrawal of GC preparations

Patient P. 22 years old, subacute SLE. "Withdrawal syndrome" in 1974 was caused by the forced abolishment of GCs (hatched) because of development of aseptic osteonecrosis of the femoral bone heads. The dotted lines show the limits of normal values of blood tyrosine. 
Tyrosine-based comment. The 22-year-old girl became invalid as a result of GC therapy. But if blood tyrosine had been adopted for monitoring GC therapy, the dose of GCs should be decreased (or they even could be abolished?) in 1973, before the development of osteonecrosis!

\section{Discussion}

Glucocorticoid hormones synthesized in the adrenal cortex do not have specific target organ, but their receptors are found in all tissues and organs. This ensures an extremely broad range of metabolic and physiological effects of GCs, they are really total action hormones and play very essential, if not the crucial, role in supporting homeostasis. In addition to supporting homeostasis at physiological rest, GCs play an extremely important role in situations when physical and/or mental efforts are required, under stress conditions, and in diseases caused by various agents. In such situations, the secretion of GCs by the adrenal cortex increases and their blood level can be tenfold higher than at rest. GCs act as a natural doping.

More than 70 years ago, Dr. Hench realized a brilliant idea: he made GC hormones to act for their evolutionary intended purpose, as a doping under stress situation - in disease [1]. GCs occurred the most efficient and multisided antiinflammatory agents because they can act through all pathways developed during the evolution. It seems also that a high efficiency of artificial GC preparations is due to possibility of using the GC structure as a carrier capable to penetrate everywhere. CC preparations are widely used in all fields of medicine, but these wonderful drugs are double-edged weapon.

GC preparations cause severe complications which are caused not by their toxicity, but are associated with their hormonal nature. It is impossible to determine the best dose of GCs, because they can be favorable even at the high level of the patient's own hormones. An index of tissue real provision with these hormones similar to blood glucose versus insulin, would be of help. But insulin mainly regulates the carbohydrate metabolism, and blood glucose is just a reasonable index of its action.

GCs are really total action hormones: $4 \mathrm{mg}$ dexamethasone caused changes of 150 of 214 metabolites in 20 healthy male volunteers [25]. Nevertheless, GCs were shown to directly regulate activities of some enzymes, and its action on the hepatic enzyme tyrosine aminotransferase (TAT) [44] was rather demonstrative. TAT was successfully used as a representative index of GC action, but it could not be measured in blood that makes it inapplicable in clinical practice.

However, TAT is a key enzyme of tyrosine metabolism, and increase in blood tyrosine levels were described by some researchers in a number of diseases $(64,74-78]$. In the works $[79,80,88,89]$ published in Russian it was shown that blood tyrosine can be used as an index of GC action on metabolism and thus to be promising as a laboratory parameter for monitoring GC therapy. (Since the problems of GC therapy still existed, I republished in English the main results of these 40-year-old studies much later [133-136]). In the work [100] blood tyrosine was shown to display the most pronounced reaction to acute withdrawal of cortisol in a patient with Addison's disease. Thus, although disorders in tyrosine metabolism obviously do not contribute to pathogenesis of various diseases, its blood level in many cases can be used as a gauge-glass of the tissue provision with GCs, natural of synthetic, as a laboratory parameter for monitoring GC therapy.

It seems that the main purpose of GC therapy in non-endocrine diseases is to compensate the inability of a patient to adequately respond to the disease. Determination of blood tyrosine level would be of help in determination of the achievement of this compensation in patients treated with GC preparations.

\section{Conclusion}

- Blood tyrosine level is an index of glucocorticoid action on metabolism and of tissue provision with these hormones or preparations (on taking into account the functional competence of the liver).

- Blood tyrosine level can be used as a laboratory parameter on prescribing glucocorticoid therapy and especially on its monitoring in endocrine and especially in non-endocrine diseases (considering the liver competence!)

- Blood tyrosine level can be determined on the background of glucocorticoid therapy.

- A positive feature of blood tyrosine as of a laboratory parameter is rather narrow limits of the normal values (they may be different depending on the method of measurement) and retention of individual values. 


\section{Compliance with ethical standards.}

\section{Acknowledgements}

I am deeply grateful to all clinicians who treated the patients and helped me in understanding the clinical data.

\section{Statement of ethical approval}

The patients studied were treated as usual. There was no intervention for "scientific reason". The experiment was in correspondence with the existent requirements.

\section{References}

[1] Hench PS, Kendall EC, Slocumb CH, Polley HF. The effect of a hormone of the adrenal cortex (17-hydroxy-11dehydrocorticosterone, Compound E) and of pituitary adrenocorticotrophic hormone on rheumatoid arthritis. Preliminary report. Proc Staff Meet Mayo Clinic. 1949; 24 (1):181-197.

[2] Hench PS, Kendall EC, Slocumb CH, Polley HF. Effect of cortisone acetate and pituitary ACTH on rheumatoid arthritis, rheumatic fever, and certain other conditions; studies in clinical physiology. Arch Intern Med. 1950; 85(4):545-666.

[3] Brunsting LA, Slocumb CH, Didcoct JW. Effect of cortisone on acute disseminated lupus erythematosus. Proc Staff Meet Mayo Clinic. 1950; 25:479-482.

[4] Carryer HM, Koelsche GA, Prickman LE, et al. Effect of cortisone on bronchial asthma and hay fever occurring in subjects sensitive to ragweed pollen. Proc Staff Meet Mayo Clinic. 1950; 25:482-486.

[5] Azarnoff DI. Symposium on steroid therapy. Introduction. Med Clinic North Amer. 1973; 57(5).

[6] Liddle JW. Clinical pharmacology of the anti-inflammatory steroids. An up-to-date review of the cortisone series. Clin Pharmacol Therap. 1961; 2:615-635.

[7] Vorlaender KO. Kortisontherapie by Auto-Immun-Krankheiten. Internist.1967; 8:94-102.

[8] Albeaux-Fernet M, Gélinet M. La corticothérapie sans danger n'existe pas (Ėtude comparative des effets secondaire des différent corticoides). Sem Hôp Paris. 1960; 36:3401-3407.

[9] Sigidin YA. Corticosteroid therapy in the modern medicine. On the 25th anniversary of the first use of cortisone (Russ). Sov Med. 1974; (7):78-82.

[10] Fauci AS. 1979 Immunosuppressive and anti-inflammatory effect of glucocorticoids, in: Glucocorticoid Hormone Action. Berlin, 1979; 449-465.

[11] Sapolsky R, Romero L, Munck A. How do glucocorticoids influence stress responses? Integrating permissive, suppressive, stimulatory, and preparative actions. Endocrinol Rev. 2000; 21:55-89.

[12] Rhen T, Cidlowsky JA. Anti-inflammatory action of glucocorticoids - new mechanisms for old drugs. N Engl J Med. 2005; 353:1711-23.

[13] Kulinsky VI. Biochemical aspects of inflammation. Biochemistry (Moscow). 2007; 72(6):595-607.

[14] Ramamoorphy S, Cidlowsky J. Corticosteroids: Mechanisms of action in health and disease. Rheum Clin North Am. 2018; 42:15-31.

[15] Vandewalle J, Luypaert A, De Bussher K, Libert C. Therapeutic mechanisms of glucocorticoids. Trends Endocrinol Metab. 2018; 29 (1):42-54.

[16] Schäcke H, Schottelius A, Docke W, et al. Dissociation of transactivation from transrepression by a selective glucocorticoid agonist leads to separation of therapeutic effects from side effects. Proc Natl Acad Sci USA. 2004; 101:227-232.

[17] Zimmermann C, Avery W, Finelli A, et al. Selective amplification of glucocorticoid anti-inflammatory activity through synergistic multi-target action of a combination drug. Arthr Res Ther. 2009; 11:12-26.

[18] Vandevyver S, Dejager L, Tuckermann J, Libert C. New insights into the anti-inflammatory mechanisms of glucocorticoids: An emerging role for glucocorticoid-receptor-mediated transactivation. Endocrinology. 2013; 154:993-1007. 
[19] Kavanagh RJ, Kam, PCA. Lazaroids: efficacy and mechanism of action of 21-aminosteroids in neuroprotection. Br J Anaesth. 2001; 86(1):110-119.

[20] Carratu MR. Lazaroids and neuroprotection: What benefit? J Pharmacol Clin Res. 2017; 2(2): Editorial.

[21] Ozbakir B, Crielaard BJ, Metselaar JM, et al. Liposomal corticosteroids for the treatment of inflammatory disorders and cancer. J Control Release. 2014; 190:624-636.

[22] Perreti M, D-Acquisto F. Novel aspects of annexin 1 and Glucocorticoid biology: intersection with nitric oxide and the lipoxin receptor. Review. Inflamm Allergy Drug Targets. 2006; 5(2):107-114.

[23] Sundahl N, Bridelance J, Libert C, et al. Selective glucocorticoid receptor modulation: New directions with nonsteroidal scaffolds. Pharmacol Therapeutics. 2015; 152:28-41.

[24] Buttgereit F, Spies CM, Bijlsma JW. Novel glucocorticoids: where are we now and where do we want to go? Clin Exp Immunol. 2015; 33 (4 Suppl. 92):29-33.

[25] Bordag N, Klie S, Jürchott K, et al. Glucocorticoid (dexamethasone)-induced metabolome changes in healthy males suggest prediction of response and side effects. Sci Rep. 2015; 5, Nov 3:15954.

[26] Caplan A, Fett N, Rosenbach M, Werth VP, Micheletti, RG. Prevention and management of glucocorticoid-induced side effects: A comprehensive review: A review of glucocorticoid pharmacology and bone health. J Am Acad Dermatol. 2017; 76:1-9.

[27] Yasir M, Goyal A, Bansal P, Santhalia S. Corticosteroid Adverse Effects, Last up-date: July 4. 2020, StatPearls (Internet).

[28] Baxter J, Rousseau G. Glucocorticoid hormone action: An overview. In: Glucocorticoid Hormone Action, Baxter J, Rousseau G, Eds. Springer Verlag. 1979; 1-24.

[29] Patel R, Williams-Dautovich J, Cummins C. Minireview: New molecular mediators of glucocorticoid receptor activity in metabolic tissues. Mol Endocrinol. 2014; 28:999-1011.

[30] Ingle D. The role of adrenal cortex in homeostasis. J Endocrinol. 1952; 8:23-37.

[31] Rose A, Herzig S. Metabolic control through glucocorticoid hormones: an update. J Mol Cell Endocrinol. 2013; 380:65-78.

[32] Kuo T, McQueen A, Chen TC, Wang JC. Regulation of glucose homeostasis by glucocorticoids. Adv Exp Med Biol. 2015; 872:99-126.

[33] Nicolaides NC, Charmandari E, Chrousos GP. Overview of glucocorticoids, in: Encyclopedia of Endocrine Diseases (Second Edition) 2018; 64-71.

[34] Beisel W, Rappoport M. Interrelations between adrenocortical functions and infectious illnesses. New Engl J Med. 1969; 280:541-604.

[35] Nicolaides N, Kuratzi E, Lamprokostopoulu A, et al. Stress, the stress system and the role of glucocorticoids. Neuroimmunomodulation. 2015; 22:6-19.

[36] Dougherty TF, Brown HE, Berliner DL. Metabolism of hydrocortisone during inflammation. Endocrinology. 1958; 62:455-462.

[37] Sutton JR, Casey JH. The adrenocortical response to competitive athletics in veteran athletes. J Clin Endocrinol Metab. 1975; 40:135-138.

[38] Kass E, Finland M. Corticosteroids and infections. Adv Int Med. 1958; 9:45-80.

[39] Haleem, M, Minton, S. Effects of adrenalectomy on Trypanosoma lewisi infection in white mice. J Tropic Med. 1966; 69:294-298.

[40] Walzer PD, Powell RD, Joneda K. 1979 Experimental Pneumocystis carinii pneumonia in different strains of cortisonized mice. Infect Immunol. 1979; 24:939-947.

[41] Tsukhno ZI, Slavnov VN, Panchenko NI, et al. Functional Investigation Methods in Endocrinology (Russ). Kiev. 1981.

[42] Rozen VB. Fundamentals of Endocrinology (Russ). Moscow: 1980.

[43] Knox W. 1955 Metabolism of phenylalanine and tyrosine. In: Symposium on Amino Acid Metabolism. Baltimora. 1955; 836-866. 
[44] Lin EC, Knox WE. Adaptation of the rat liver tyrosine-alpha-ketoglutarate transaminase. Biochim Biophys Acta. $1957 ; 26: 85-88$.

[45] Kenney FT, Flora RM. Induction of tyrosine-alpha-ketoglutarate transaminase. J Biol Chem. 1957; 236:26992703.

[46] Rosen F, Nichol C. Corticosteroids and enzyme activity, Vitamins Hormones. 1963; 21:135-214.

[47] Baxter JD, Forsham PH. Tissue effects of glucocorticoids. Am J Med. 1972; 53:573-589.

[48] Gelehrter T. Mechanisms of hormonal induction of enzymes. Metabolism. 1973; 22:85-100.

[49] Protasova TN. Hormonal Regulation of Enzyme Activities (Russ). Moscow. 1975.

[50] Feigelson M, Feigelson P. Relationships between hepatic enzyme induction, glutamate formation, and purinenucleotide biosynthesis in glucocorticoid action. J Biol Chem. 1966; 241:5819-5826.

[51] Baxter J, Tomkins G. The relationship between glucocorticoid binding and tyrosine aminotransferase induction in hepatoma tissue cells. Proc Natl Acad Sci USA. 1970; 65:709-715.

[52] Beato M, Kalimi M, Feigelson P. Correlation between glucocorticoid binding to specific cytosol receptors and enzyme induction in vivo, Biochem Biophys Res Commun. 1972; 47:1464-1472.

[53] Gelehrter T, MacDonald R. Steroid specificity of the glucocorticoid inhibition of amino acid transport in rat hepatoma cells, Endocrinology. 1981; 109:476-482.

[54] Thompson E. Glucocorticoid induction of tyrosine aminotransferase in cultured cells. In: Glucocorticoid Hormone Action. Springer Verlag. 1979; 203-213.

[55] Hashimoto S, Schmidt W, Schütz G. Transcriptional activation of the rat liver tyrosine aminotransferase gene by cAMP. Proc Natl Acad Sci USA. 1984; 81(21):6637-6641.

[56] Sun Y, DuBois D, Almon R, et al. Dose-dependence and repeated-dose studies for receptor/gene-mediated pharmacodynamics of methylprednisolone on glucocorticoid receptor down-regulation and tyrosine aminotransferase induction in rat liver. J Pharmacokin Biopharmacol. 1998; 26:619-648.

[57] Grange T, Cappabianca L, Flavin M, et al. In vivo analysis of the model tyrosine aminotransferase gene reveals multiple sequential steps in glucocorticoid receptor action. Oncogene. 2001; 20:3028-3038.

[58] Sevaljević L, Isenović E, Vulović M, et al. The responses of rat liver glucocorticoid receptors and genes for tyrosine aminotransferase alpha-2-macroglobulin and gamma-fibrinogen to adrenalectomy-, dexamethasone- and inflammation-induced changes in the levels of glucocorticoids and proinflammatory cytokines. Bio Signal Recept. 2001; 10(5):299-309.

[59] Hazra A, Pyszeznsli N, DuBois D, et al. 2007 Modeling, receptor/gene-mediated effect of corticosteroids on hepatic tyrosine aminotransferase dynamics in rats: dual regulation by exogenous corticosteroids. J Pharmacokin Pharmacodynam. 2007; 34 (5):643-647.

[60] Braunstein AE. Biochemistry of Amino Acid Metabolism (Russ). Moscow. 1969; 270- 293.

[61] La Du BN, Zannoni VG, Laster L, Seegmiller JE. The nature of the defect in tyrosine metabolism in alcaptonuria. J Biol Chem. 1958; 230:251-260.

[62] Armstrong M, Stave U. A study of plasma free amino acid levels. II. Normal values for children and adults. Metabolism. 1973a; 22:561-569.

[63] Rivlin R, Melmon K. 1965 Cortisone-provoked depression of plasma tyrosine concentration: relation to enzyme induction in man. J Clin Invest. 1965; 44:1690-1698.

[64] Kainova AS. Amino acid metabolism in patients with collagenoses (Russ), Vopr Revmatizma. 1974; no 1:68-73.

[65] Armstrong M, Stave U. A study of plasma free amino acid levels. IV. Characteristic individual levels of the amino acids. Metabolism. 1973b; 22:821-825.

[66] Betheil J, Feigelson M, Feigelson P. The differential effect of glucocorticoids on tissue and plasma amino acid levels. Biochem Biophys Acta. 1965; 104:92-97.

[67] Pitot HC, Yatvin MB. Interrelationships of mammalian hormones and enzyme levels in vivo. Physiol Rev. 1973; 53:228-325.

[68] Derks M, Dubois E, Koomans P, Boxtel C. Effect of hydrocortisone on plasma tyrosine concentration and lymphocyte counts in healthy volunteers. Clin Drug Invest. 1999; 18:391-401. 
[69] Nemeth S. The effect of stress or glucose feeding on hepatic tyrosine aminotransferase activity and liver and plasma tyrosine level of intact and adrenalectomized rats. Horm Metabol Res. 1978; 10:144-147.

[70] Selye H. The Physiology and Pathology of Exposure to Stress. Montreal, 1950.

[71] Levine R, Conn HO. Tyrosine metabolism in patients with liver disease. J Clin Invest. 1968; 46:2012-2020.

[72] Nordlinger BM, Fulenwider JT, Ivey JI, et al. Tyrosine metabolism in cirrhosis, J Lab Clin Med. 1979; 94:832-840.

[73] Clayton T, Lindon J, Everett, J, et al. Hepatotoxin-induced hypertyrosinemia and its toxicological significance. Arch Toxicol. 2007; 81:201-210.

[74] Nishimura N, Yasui M, Okamoto $\mathrm{H}$, et al. Intermediary metabolism of phenylalanine and tyrosine in diffuse collagen diseases. Arch Dermatol. 1958; 77:255-267.

[75] Nishimura N, Maeda K, Yasui M, et al. Phenylalanine and tyrosine in collagen diseases. Arch Dermatol. 1961; 83:644-652.

[76] Kainova AS, Kvyatkovskaya AN. Disorders in aromatic acid metabolism in rheumatism (Russ). Terap. Arch. 1965; no 11:44-52.

[77] Demin AA, Zhuk RD. Amino acid composition and blood serum proteins in collagenoses and rheumatism (Russ). Trudy I MMI. 1966; 48:50-506.

[78] Dovgallo, GK, Goncharik, II. 1973 Disorders in aromatic acid metabolism in patients with rheumatoid arthritis (Russ). Terap Arkh. 1973; no 11:86-91.

[79] Rass IT, Borisov IA, Nikishova TA, Sura VV. Blood tyrosine dynamics and treatment with corticosteroids in systemic lupus erythematosus (Russ). Terap Arkh. 1977; 59(80):110-115.

[80] Rass IT. Using corticosteroid hormones and tyrosine metabolism (Russ). Patol Fiziol. 1978; no. 2:87-91.

[81] Udenfriend S, Cooper J. The chemical estimation of tyrosine and tyramine. J Biol Chem. 1952; 196(1):227-233.

[82] Lascano-Gonzales JM. Les surrénales assesoires chez le Rat blanc. C R Soc Biol. 1932; 116:451-454.

[83] Panov AN, Shalyapina VG. Dynamics of 11-hydroxycorticosteroid level in peripheral blood of rats after injection of different doses of hydrocortisone and corticosterone (Russ), Probl Endokrinol. 1968; no. 2:75-77.

[84] Geller E, Yuwiler A, Schapiro S. Tyrosine aminotransferase activation or repression by a stress, Proc Soc Exper Biol. 1969; 130:458-461.

[85] Buckingam JC, Hodges JR. Interrelationships of pituitary and plasma corticotrophin and plasma corticosterone in adrenalectomized and stressed, adrenalectomized rats. J Endocrinol. 1974; 63:213-222.

[86] Fazekas JB. Uber die Mobilisierbarkeit des Korticosterongehalten des "Peripherishen Hormondepots". Endokrinologie. 1964; 46: 133-138.

[87] Ptak W. The effect of stress on the steroid hormone content in the brown adipose tissue of the rat. Folia Biol. 1962; 10:131-135.

[88] Rass IT. Changes in blood tyrosine content in rats upon adrenalectomy and on substitutive injections of hydrocortisone (Russ) Dokl Akad Nauk SSSR. 1980; 250(6):1497-1499.

[89] Rass IT, Kuznetsova ES, Zhukovsky MA. Blood tyrosine as an index of adequacy of the glucocorticoid replacement therapy in children with congenital adrenal hyperplasia (Russ) Pediatriya. 1979; 58(9):26-29.

[90] Lukert BP. Editorial: glucocorticoid replacement - How much is enough? J Clin Endocrinol Metab. 2006; 91(3):793-794.

[91] Bongiovanni AM, Eberlein MR. Defects of steroidal metabolism in subjects with adrenogenital syndrome. Metabolism. 1961; 10:917-935.

[92] Zhukovsky MA, Buraya TI, Kuznetsova ES. Inborn Dysfunctions of Adrenal Cortex in Children (Russ). Moscow. 1977.

[93] Merke DP, Bornstein SR. Congenital adrenal hyperplasia. Lancet. 2005; 365 (9477):2125-2136.

[94] Lo JC, Schwitzgebel VM, Tyrrell JB, et al. Normal female infants born of mothers with classic congenital adrenal hyperplasia due to 21-hydroxylase deficiency, J Clin Endocrinol Metab. 1999; 84(3):930-936.

[95] Brook CCD. Congenital adrenal hyperplasia. In: The Human Adrenal Gland. London, 1979; 243-258. 
[96] Bonfig W, Dalla Pozza S, Schmidt H, et al. Hydrocortisone dosing during puberty in patients with congenital adrenal hyperplasia: An evidence-based recommendations, J Clin Endocrinol Metab. 2009; 94(10):3882-3888.

[97] Whittle E, Falhammar H. Glucocorticoid regimen in the treatment of congenital adrenal hyperplasia: A systematic review and meta-analysis. J Endocrinol Soc. 2019; 3(6):1227-1245.

[98] Ten S, New M, Maclaren N. Addison's Disease 2001. J Clin Endocrinol Metab. 2001; 86(7):2909-2922.

[99] Snell RS. Hormonal control of pigmentation in man and other animals, Adv Biol Skin. 1967; 8:447-466.

[100] Christiansen JJ, Djurhuus CB, Gravholt CH, et al. Effects of cortisol on carbohydrate, lipid, and protein metabolism: Studies of acute cortisol withdrawal in adrenocortical failure. J Clin Endocrinol Metab. 2007; 92(9):3553-3559.

[101] Dahl R. Systemic side effects of inhaled corticosteroids in patients with asthma. Respirat Med. 2005; 100:13071317.

[102] Crofton J, Douglas A. Bronchial asthma, in: Respiratory Diseases. Oxford. 1975; 429-460.

[103] Don H. Management of status asthmaticus, in: Bronchial Asthma: Principles of Diagnosis and Treatment. NY. 1981; 363-383.

[104] Lipworth BJ. Clinical pharmacology of corticosteroids in bronchial asthma. Pharmacol Therap. 1993; 58(2):173209.

[105] Alangari AA. Corticosteroids in the treatment of acute asthma. Ann Thorac Med. 2014; 9(4):187-192.

[106] Dunican EM, Fahy JV. Asthma and corticosteroids: time for a more precise approach to treatment. Eur Respirat J. 2017; 49: DOI: 10.1183/13993003.01167-2017.

[107] Cayton RM, Howard P. Plasma cortisol and the use of hydrocortisone in the treatment of status asthmaticus. Thorax. 1973; 28:567-573.

[108] Morrish DW, Sproule BJ, Aaron TH, et al. Hypothalamic-pituitary-adrenal function in extrinsic asthma. Chest. $1979 ; 75: 161-166$.

[109] Karalus NC, Mahood CB, Dunn PJ, Speed JF. Adrenal function in acute severe asthma. NZ Med J. 1985; 98(788): 843-846.

[110] Roberts S, Sutherland T, Slough J, et al. Adrenal insufficiency in asthma patients - Who is at risk? Eur Respirat J. 2016; 48: PA4899; DOI: 10.1183/13993003.congress-2016.PA4899.

[111] Chodosowska E. Exercise-induced bronchoconstriction in patients with bronchial asthma. Its prevention with anti-histaminic agent. Respiration. 1977; 34:31-35.

[112] Vink NM, Boesen HM, Postma DS, et al. Basal or stress-induced cortisol and asthma development: the TRAILS study. Eur Respirat J. 2013; 41:846-852; DOI: $10.1183 / 09031936.00021212$

[113] Rass IT, Bunyatyan AF, Kornev BM, Turusina TA. Tyrosine, 11-oxycorticosteroids, and cortisol in blood of patients with bronchial asthma (Russ). Terap Arkh. 1978; 60(11):98-101.

[114] Pavlikhina LV, Usvatova IY, Bunyatyan AF. Fluorometric method of separate determination of free and proteinbound proteins in blood plasma, in: Methods of Investigation of Some Systems of Hormonal Regulation (Russ). Moscow, 1967; 50-59.

[115] Dubois EL. Lupus Erythematosus. McGraw Hill. 1966.

[116] Dubois EL. Lupus Erythematosus. 2nd edition. Los Angeles. 1974.

[117] Schroeder J, Euler H. Recognition and management of systemic lupus erythematosus. Drugs. 1977; 54:422-434.

[118] Ioannou Y, Isenberg DA. Current concepts for the management of systemic lupus erythematosus in adults: a therapeutic challenge, Postgrad Med. 2002; 78:599-606.

[119] Godblatt F, Isenberg DA. New therapies for systemic lupus erythematosus, Clin Exp Immunol. 2005; 40:205-212.

[120] Nived O, Sturfelt G, Bengtsson AA. Improved lupus outcome. We are doing a good job, but could we do better? J Rheumatol. 2008; 59:176-180.

[121] Ntali S, Tzanakakis M, Bertsias G, et al. What's new in clinical trials in lupus? Int J Clin Rheumatol., 2009; 4(4):473485.

[122] Hashimoto H. Glucocorticoid therapy in systemic lupus erythematosus - Clinical analysis of 1,125 patients with SLE.| In: TechOpen Published, 2012; 2012-11-28. 
[123] Durcan L, O’Dwyer T. Management strategies and future directions for systemic lupus erythematosus in adults. Lancet. June 2019; 393 (10188):2332-2343. DOI: 10. 1016/S0140-6736(19)30237-5.

[124] Luijten R, Fritsch-Stork R, Bijlsma J, et al. The use of glucocorticoids in systemic lupus erythematosus. After 60 years still more an art than science. Autoimmun Res. 2013; 12:617-628.

[125] Stojan G, Petri M. The risk benefit ratio of glucocorticoids in SLE: have things changed over the past 40 years? Curr Treatm Opt Rheumatol. 2017; 3(3):164-172.

[126] Apostolopoulos D, Morand EF. It hasn't gone away: the problem of glucocorticoid use in lupus remains. Rheumatology (Oxford). 2017; 56 (Suppl_1):i114-i122.

[127] Bazsó A, Szappanos A, Patós A, et al. The importance of glucocorticoid receptors in systemiMODUSc lupus erythematosus. A systematic review. Autoimmunity Revs. 2015; 14 (4):349-351.

[128] Rahman A, Isenberg DA. Systemic lupus erythematosus. N Engl J Med. Febr 28 2008; 358:929-939.

[129] Cohen PL. T- and B-cell abnormalities in systemic lupus. J Invest Dermatol. 1993; 100(1): 69-72.

[130] Suárez-Fueyo A, Bradley SJ, Tsokos GC. T cells in systemic lupus erythematosus. Curr Opin Immunol. 2016; 43:3238.

[131] Tsai CY, Li KJ, Hsieh SC, et al. What's wrong with neutrophils in lupus? Clin Exp Rheumatol. 2019; 37(4): 684-693.

[132] P.S. Since the problem of glucocorticoid safety continued to exist, I wrote some papers (including the present manuscript) much later.

[133] Rass IT. Blood content of tyrosine is an index of glucocorticoid action on metabolism. Biochemistry (Moscow). 2010; 75 (3): 353-366.

[134] Rass IT. Tyrosine-based monitoring of glucocorticoid therapy of systemic lupus erythematosus. In: SYSTEMIC LUPUS ERYTHEMATOSUS. 2012; Almoalim H. ed: 163-184.

[135] Irma Th. Rass. Can we tame glucocorticoids? Blood tyrosine as a new laboratory test. 2016: J Biomol Res Therap. 2016; 5:2: 1-6 (open access).

[136] Irma Th. Rass. Adrenocortical response in influenza as a pattern for using corticosteroids in COVID-19. GSC Biol Pharm Sci. 2020; 12(03): 098-101. 